\title{
Generalized net model of a biometric authentication system based on palm geometry and palm vein matching using intuitionistic fuzzy evaluations
}

\author{
Zhelyana Ivanova $^{1}$ and Veselina Bureva ${ }^{2}$ \\ 1 "Prof. Dr. Assen Zlatarov" University \\ 1 "Prof. Yakimov" Blvd., Burgas 8010, Bulgaria \\ e-mail: zhelyana.ivanovaeabv.bg \\ 2 "Prof. Dr. Assen Zlatarov" University \\ 1 "Prof. Yakimov" Blvd., Burgas 8010, Bulgaria \\ e-mail: vbureva@btu.bg
}

Received: 4 May 2020

Revised: 7 September 2020

Accepted: 5 October 2020

\begin{abstract}
In the current research work a multimodal biometric system is investigated. It combines the palm vein authentication and palm geometry recognition methods. The system will be used to manage the access control. The apparatus of generalized nets is applied to model the biometric authentication processes. The constructed generalized net model of biometric authentication system based on palm geometry and palm vein matching using intuitionistic fuzzy evaluations can be used for simulation of the real processes. The intuitionistic fuzzy evaluations are used to compare the user traits with the templates stored in database.
\end{abstract}

Keywords: Biometrics, Generalized nets, Intuitionistic fuzzy sets, Palm vein authentication, Palm geometry authentication.

2010 Mathematics Subject Classification: 03E72, 68Q85.

\section{Introduction}

The standard process of biometric pattern recognition problem contains a sequence different stages: acquisition, image quality assessment, preprocessing, region of interest (RoI) determination (templates), feature extraction and biometric comparison. Types of biometric authentication methods include face recognition, fingerprint recognition, eyes-retina-iris 
recognition, ear recognition, hand geometry recognition, odor identification, vein recognition, gait recognition, typing recognition, voice - speaker authentication, signature recognition and etc. Depending of the traits for capturing the algorithm can be modified. Hand-based biometric systems measure and analyze the structure, shape and proportions of the hand or extract characteristics of the skin surface of the palm. The scan devices are measuring and recording the length, width, thickness, and surface area of the hand of an individual. Hand geometry systems use a camera to capture a silhouette image of the hand. Palm vein authentication uses palm veins as the biometric feature. In the palm vein scan the infrared light maps the unique vein structure of the palm. The infrared light observes the palm vein, which is normally unobservable by the human eye. The similarity between the captured palm vein and the template stored in the database can be calculated using different methods. The resulting similarity score is verified using predetermined threshold [18].

\section{Generalized net model of biometric authentication system based on palm geometry and palm vein matching using intuitionistic fuzzy evaluations}

The theory of Genelarized Nets (GNs) is introduced in [1, 6, 7]. GN models for pattern recognition processes are published $[2-5,10]$. GN model of biometric access-control system and GN model of multimodal biometric systems are constructed $[2,8]$. The biometric methods as iris recognition [11, 17], face recognition [14-16], fingerprints recognition [9] and signature verification [10], image classification [13] are already modeled using the apparatus of GNs. In the current paper a generalized net model of biometric authentication system based on palm geometry and palm vein matching using intuitionistic fuzzy evaluations is constructed using GNDraw software [12]. It contains 9 transitions and 39 places (Fig. 1). The set of transitions A has the following form:

$$
A=\left\{Z_{1}, Z_{2}, Z_{3}, Z_{4}, Z_{5}, Z_{6}, Z_{7}, Z_{8}, Z_{9}\right\}
$$

where the transitions describe the following processes:

- $Z_{1}$ - users;

- $Z_{2}$ - scanning the user traits: palm vein trait and palm geometry trait;

- $Z_{3}$ - image quality assessment and preprocessing the palm vein and palm geometry images;

- $Z_{4}$ - region of interest (RoI) determination and palm vein templates extracting;

- $Z_{5}$ - region of interest (RoI) determination and palm geometry templates extracting;

- $Z_{6}$ - storing templates and passwords in database;

- $Z_{6}$ - passwords validation;

- $Z_{8}$ - biometric comparison (pattern matching);

- $Z_{9}$ - calculating intuitionistic fuzzy evaluations.

Initially, there is one $\alpha_{14}$-token that is located in place $L_{28}$ with initial characteristic: "database". In the next time-moments this token is split into two or more. The original $\alpha_{14}$-token will continue to stay in place $l_{28}$, while the other $\alpha$-tokens will move to the next transitions. 


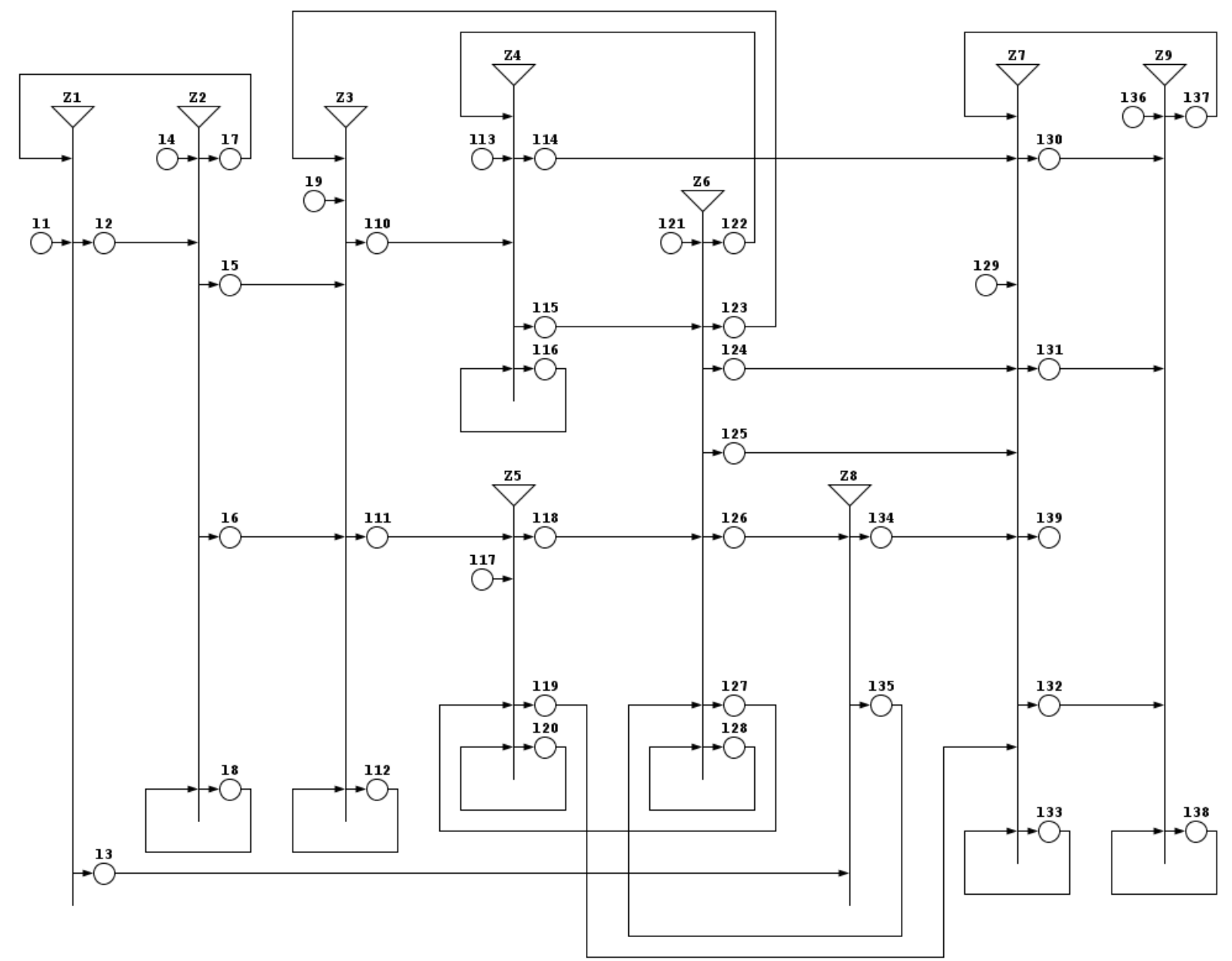

Figure 1. Generalized net model of biometric authentication system based on palm geometry and palm vein matching using intuitionistic fuzzy estimations

The token $\alpha_{1}$ enters the net via place $l_{1}$ with initial characteristic: "user".

The transition $Z_{1}$ has the form:

$$
Z_{1}=\left\langle\left\{l_{1}, l_{7}\right\},\left\{l_{2}, l_{3}\right\}, R_{1}, \vee\left(l_{1}, l_{7}\right)\right\rangle,
$$

where:

$$
R_{1}=\begin{array}{c|cc} 
& l_{2} & l_{3} \\
\hline l_{1} & W_{1,2} & W_{1,3} \\
l_{7} & \text { true } & \text { false }
\end{array}
$$

and

- $W_{1,2}=$ "there are user for scanning";

- $W_{1,3}=$ "there are user for password".

The $\alpha$-tokens that enter places $l_{2}$ and $l_{3}$ have the following characteristics: "user for scanning" in place $l_{2}$, and "user for password" in place $l_{3}$.

The token $\beta_{1}$ enters the net via place $l_{4}$ with initial characteristic: "scanning parameters".

The transition $Z_{2}$ has the form:

where:

$$
Z_{2}=\left\langle\left\{l_{2}, l_{4}, l_{8}\right\},\left\{l_{5}, l_{6}, l_{7}, l_{8}\right\}, R_{2}, \vee\left(\wedge\left(l_{2}, l_{4}\right), l_{8}\right)\right\rangle,
$$


and

$R_{2}=$\begin{tabular}{c|cccc} 
& $l_{5}$ & $l_{6}$ & $l_{7}$ & $l_{8}$ \\
\hline$l_{2}$ & false & false & false & true \\
$l_{4}$ & false & false & false & true \\
$l_{8}$ & $W_{8,5}$ & $W_{8,6}$ & $W_{8,7}$ & $W_{8,8}$
\end{tabular}

- $W_{8,5}=$ "there is scanned palm geometry";

- $W_{8,6}=$ "there is scanned palm vein";

- $W_{8,7}=$ "the user traits is needed to scan again";

- $W_{8,8}=\neg\left(W_{8,5} \wedge W_{8,6} \wedge W_{8,7}\right)$.

The $\alpha$-tokens that enter in the places $l_{5}, l_{6}$ and $l_{7}$ have the following characteristics:

- "scanned palm geometry" in place $l_{5}$,

- "scanned palm vein" in place $l_{6}$, and

- "the user traits to scan again" in place $l_{7}$.

The token $\beta_{2}$ enters the net via place $l_{9}$ with initial characteristic: "parameters for preprocessing".

The transition $Z_{3}$ has the form:

$$
Z_{3}=\left\langle\left\{l_{5}, l_{6}, l_{9}, l_{12}, l_{23}\right\},\left\{l_{10}, l_{11}, l_{12}\right\}, R_{3}, \vee\left(\wedge\left(l_{5}, l_{6}, l_{9}, l_{23}\right), l_{12}\right)\right\rangle,
$$

where:

$R_{3}=$\begin{tabular}{c|ccc} 
& $l_{10}$ & $l_{11}$ & $l_{12}$ \\
\hline$l_{5}$ & false & false & true \\
$l_{6}$ & false & false & true \\
$l_{9}$ & false & false & true \\
$l_{12}$ & $W_{12,10}$ & $W_{12,11}$ & $W_{12,12}$ \\
$l_{23}$ & false & false & true
\end{tabular}

and

- $W_{12,10}=$ "there are preprocessed palm vein images";

- $W_{12,11}=$ "there are preprocessed palm geometry images";

- $W_{12,12}=\neg\left(W_{12,10} \wedge W_{12,11}\right)$.

The $\alpha$-tokens that enter places $l_{10}$ and $l_{11}$ have the following characteristics: "preprocessed palm vein images" in place $l_{10}$, and "preprocessed palm geometry images" in place $l_{11}$.

The token $\beta_{3}$ enters the net via place $l_{13}$ with initial characteristic: "parameters for palm vein templates extraction".

The transition $Z_{4}$ has the form:

$$
Z_{4}=\left\langle\left\{l_{10}, l_{13}, l_{16}, l_{22}\right\},\left\{l_{14}, l_{15}, l_{16}\right\}, R_{4}, \vee\left(\wedge\left(l_{10}, l_{13}, l_{22}\right), l_{16}\right)\right\rangle,
$$

where:

and

$R_{4}=$\begin{tabular}{c|ccc} 
& $l_{14}$ & $l_{15}$ & $l_{16}$ \\
\hline$l_{10}$ & false & false & true \\
$l_{13}$ & false & false & true \\
$l_{16}$ & $W_{16,14}$ & $W_{16,15}$ & $W_{16,16}$ \\
$l_{22}$ & false & false & true
\end{tabular}


- $W_{16,14}=$ "there are extracted palm vein templates for comparison";

- $W_{16,15}=$ "there are extracted palm vein templates for storing in database";

- $W_{16,16}=\neg\left(W_{16,14} \wedge W_{16,16}\right)$.

The $\alpha$-tokens that enter in the places $l_{14}$ and $l_{15}$ have the following characteristics: "extracted palm vein templates for comparison" in place $l_{10}$ and "extracted palm vein templates for storing in database" in place $l_{11}$.

The token $\beta_{4}$ enters the net via place $l_{17}$ with initial characteristic: "parameters for palm geometry extraction".

The transition $Z_{5}$ has the form:

$$
Z_{5}=\left\langle\left\{l_{11}, l_{17}, l_{20}, l_{27}\right\},\left\{l_{18}, l_{19}, l_{20}\right\}, R_{5}, \vee\left(\wedge\left(l_{11}, l_{17}, l_{27}\right), l_{20}\right)\right\rangle,
$$

where:

$R_{5}=$\begin{tabular}{c|ccc} 
& $l_{18}$ & $l_{19}$ & $l_{20}$ \\
\hline$l_{11}$ & false & false & true \\
$l_{17}$ & false & false & true \\
$l_{20}$ & $W_{20,18}$ & $W_{20,19}$ & $W_{20,20}$ \\
$l_{27}$ & false & false & true
\end{tabular}

and

- $W_{20,18}=$ "there are extracted palm geometry templates for storing in database";

- $W_{20,19}=$ "there are extracted palm geometry templates for comparison";

- $W_{20,20}=\neg\left(W_{20,18} \wedge W_{20,19}\right)$.

The $\alpha$-tokens that enter places $l_{18}$ and $l_{19}$ have the following characteristics: "extracted palm geometry templates for storing in database" in place $l_{18}$ and "extracted palm geometry templates for comparison" in place $l_{19}$.

The token $\beta_{5}$ enters the net via place $l_{21}$ with initial characteristic: "previously generated user traits data and passwords".

The transition $Z_{6}$ has the form:

$$
Z_{6}=\left\langle\left\{l_{15}, l_{18}, l_{21}, l_{28}, l_{35}\right\},\left\{l_{22}, l_{23}, l_{24}, l_{25}, l_{26}, l_{27}, l_{28}\right\}, R_{6}, \vee\left(l_{15}, l_{18}, l_{21}, l_{28}, l_{35}\right)\right\rangle,
$$
where:

$R_{6}=$\begin{tabular}{c|ccccccc} 
& $l_{22}$ & $l_{23}$ & $l_{24}$ & $l_{25}$ & $l_{26}$ & $l_{27}$ & $l_{28}$ \\
\hline$l_{15}$ & false & false & false & false & false & false & true \\
$l_{18}$ & false & false & false & false & false & false & true \\
$l_{21}$ & false & false & false & false & false & false & true \\
$l_{28}$ & $W_{28,22}$ & $W_{28,23}$ & $W_{28,24}$ & $W_{28,25}$ & $W_{28,26}$ & $W_{28,27}$ & $W_{28,28}$ \\
$l_{35}$ & false & false & false & false & false & false & true
\end{tabular}

and

- $W_{28,22}=$ "the palm vein templates extraction is needed";

- $W_{28,23}=$ "there are templates for preprocessing";

- $W_{28,24}=$ "there are palm vein templates for comparison";

- $W_{28,25}=$ "there are palm geometry templates for comparison";

- $W_{28,26}=$ "there are password"; 
- $\quad W_{28,27}=$ "the palm geometry templates extraction is needed";

- $W_{28,28}=\neg\left(W_{28,22} \wedge W_{28,23} \wedge W_{28,24} \wedge W_{28,25} \wedge W_{28,26} \wedge W_{28,27}\right)$.

The $\alpha$-tokens that enter places $l_{22}, l_{23}, l_{24}, l_{25}, l_{26}$ and $l_{27}$ have the following characteristics:

- "demand of palm vein templates extraction" in place $l_{22}$,

- "templates for preprocessing" in place $l_{23}$,

- "palm vein templates for comparison" in place $l_{24}$,

- "palm geometry templates for comparison" in place $l_{25}$,

- "password" in place $l_{26}$ and

- "demand of palm geometry templates extraction" in place $l_{27}$.

The token $\beta_{6}$ enters the net via place $l_{29}$ with initial characteristic: "parameters for pattern matching".

The transition $Z_{7}$ has the form:

$$
\begin{gathered}
Z_{7}=\left\langle\left\{l_{14}, l_{19}, l_{24}, l_{25}, l_{29}, l_{33}, l_{34}, l_{37}\right\},\left\{l_{30}, l_{31}, l_{32}, l_{33}, l_{39}\right\}, R_{7},\right. \\
\left.\vee\left(\wedge\left(l_{14}, l_{19}, l_{24}, l_{25}, l_{29}, l_{34}, l_{37}\right), l_{33}\right)\right\rangle,
\end{gathered}
$$

\begin{tabular}{|c|c|c|c|c|c|}
\hline & $l_{30}$ & $l_{31}$ & $l_{32}$ & $l_{33}$ & $l_{39}$ \\
\hline$l_{14}$ & false & false & false & true & false \\
\hline$l_{19}$ & false & false & false & true & false \\
\hline$l_{24}$ & false & false & false & true & false \\
\hline$l_{25}$ & false & false & false & true & false \\
\hline$l_{29}$ & false & false & false & true & false \\
\hline$l_{33}$ & $W_{33,30}$ & $W_{33,31}$ & $W_{33,32}$ & $W_{33,33}$ & $W_{33,39}$ \\
\hline$l_{34}$ & false & false & false & true & false \\
\hline$l_{37}$ & false & false & false & true & false \\
\hline
\end{tabular}

where:

and

- $\quad W_{33,30}=$ "there are palm vein patterns for intuitionistic fuzzy estimation";

- $W_{33,31}=$ "there are palm geometry patterns for intuitionistic fuzzy estimation";

- $W_{33,32}=$ "there are password for intuitionistic fuzzy estimation";

- $W_{33,39}=$ "there are result of pattern matching using intuitionistic fuzzy estimation";

- $W_{33,39}=\neg\left(W_{33,30} \wedge W_{33,31} \wedge W_{33,32} \wedge W_{33,39}\right)$.

The $\alpha$-tokens that enter in the places $l_{30}, l_{31}, l_{32}$ and $l_{39}$ have the following characteristics:

- "palm vein patterns for intuitionistic fuzzy estimation" in place $l_{30}$,

- "palm geometry patterns for intuitionistic fuzzy estimation" in place $l_{31}$,

- "password for intuitionistic fuzzy estimation" in place $l_{32}$ and

- "result of pattern matching using intuitionistic fuzzy estimations" in place $l_{39}$.

The intuitionistic fuzzy evaluations of the images of palm vein, palm geometry and passwords are calculated using the following sets:

- cardinality of the set of pixels is $p$;

- cardinality of the common set of pixels in the two images $t$;

- cardinality of the set containing the different pixels from the first image $f$.

Therefore, the intuitionistic fuzzy estimations have the following form: 
- degree of membership

$$
\mu_{A}(x)=\frac{t}{p}
$$

- degree of non-membership

$$
v_{A}(x)=\frac{f}{p},
$$

- degree of uncertainty

$$
\pi_{A}(x)=1-\frac{t}{p}-\frac{f}{p} .
$$

The intuitionistic fuzzy evaluations are calculated for the palm geometry authentication, palm vein authentication and password identification.

The transition $Z_{8}$ has the form:

$$
Z_{8}=\left\langle\left\{l_{3}, l_{26}\right\},\left\{l_{34}, l_{35}\right\}, R_{8}, \vee\left(l_{3}, l_{26}\right)\right\rangle,
$$

where:

$$
R_{8}=\begin{array}{c|cc} 
& l_{34} & l_{35} \\
\hline l_{3} & \text { true } & \text { false } \\
l_{26} & W_{26,34} & W_{26,35}
\end{array}
$$

and

- $W_{26,34}=$ "there are password";

- $W_{26,35}=\neg W_{26,34}$.

The $\alpha$-token that enters place $l_{34}$ has the following characteristics: "password".

The token $\beta_{6}$ enters the net via place $l_{36}$ with initial characteristic: "formulas for intuitionistic fuzzy evaluations".

The transition $Z_{9}$ has the form:

$$
Z_{9}=\left\langle\left\{l_{30}, l_{31}, l_{32}, l_{36}, l_{38}\right\},\left\{l_{37}, l_{38}\right\}, R 9, \vee\left(\wedge\left(l_{30}, l_{31}, l_{32}, l_{36}\right), l_{38}\right)\right\rangle,
$$

where:

$R_{9}=$\begin{tabular}{c|cc} 
& $l_{37}$ & $l_{38}$ \\
\hline$l_{30}$ & false & true \\
$l_{31}$ & false & true \\
$l_{32}$ & false & true \\
$l_{36}$ & false & true \\
$l_{38}$ & $W_{38,37}$ & $W_{38,38}$
\end{tabular}

and

- $W_{38,37}=$ "there are intuitionistic fuzzy evaluations";

- $W_{38,38}=\neg W_{38,38}$.

The $\alpha$-token that enters in the place $l_{37}$ has the following characteristics: "intuitionistic fuzzy evaluations". 


\section{Conclusion}

In the present research work, a generalized net model of biometric authentication system based on palm geometry and palm vein matching using intuitionistic fuzzy evaluations is constructed. Palm geometry identification and palm vein matching are two of the main methods in the area of biometrics authentication. They are used in access control systems. The calculated intuitionistic fuzzy evaluations are used in the pattern matching phase. The constructed generalized net model of biometric authentication system based on palm geometry and palm vein matching using intuitionistic fuzzy evaluations can be applied for simulation of the real access control processes.

\section{References}

[1] Atanassov, K. (1991). Generalized nets. World Scientific, Singapore.

[2] Atanassov, K., Boumbarov, O., Gluhchev, G., Hadjitodorov, S., Shannon, A., \& Vassilev, V. (2007). A Generalized Net Model of Biometric Access-Control System. Proceedings of the 9th WSEAS International Conference on Automatic Control, Modeling \& Simulation, Istanbul, Turkey, 27-29 May 2007, 78-81.

[3] Atanassov, K., Gluhchev, G., Hadjitodorov, S., Kacprzyk, J., Shannon, A., Szmidt, E., \& Vassilev, V. (2006). Generalized Nets Decision Making and Pattern Recognition. Warsaw School of Information Technology, Warszawa.

[4] Atanassov, K., Gluhchev, G., Hadjitodorov, S., Shannon, A., \& Vasilev, V. (2005). Generalized nets in Image Processing and Pattern Recognition. Proceedings of the Sixth International Workshop on GNs, Sofia, 47-60.

[5] Atanassov, K., Gluhchev, G., Hadjitodorov, S., Shannon, A., \& Vassilev, V. (2003). Generalized Nets and Pattern Recognition. KvB Visual Concepts Pty Ltd, Monograph No. 6, Sydney.

[6] Atanassov, K., \& Sotirova, E. (2017). Generalized Nets. "Prof. Marin Drinov" Academic Publishing House, Sofia (in Bulgarian).

[7] Atanassov, K. (2007). On Generalized Nets Theory. "Prof. Marin Drinov" Academic Publishing House, Sofia.

[8] Bureva, V., Sotirova, E., \& Bozov, H. (2018). Generalized Net Model of Biometric Identification Process. Proceedings of the 20th International Symposium on Electrical Apparatus and Technologies (SIELA), Bourgas, 1-4.

[9] Bureva, V., Yovcheva, P., \& Sotirov, S. (2018). Generalized Net Model of Fingerprint Recognition with Intuitionistic Fuzzy Evaluations. In: Kacprzyk, J., Szmidt, E., Zadrożny, S., Atanassov, K., Krawczak, M. (eds), Advances in Fuzzy Logic and Technology 2017. IWIFSGN 2017, EUSFLAT 2017. Advances in Intelligent Systems and Computing Series, Springer, Vol. 641, 286-294. 
[10] Gluhchev, G., Atanassov, K., Hadjitodorov, S., \& Szmidt, E. (2009). A Generalized Net Model for Signature Verification. Proceedings of Tenth International Workshop on Generalized Nets, Sofia, 5 December 2009, 27-30.

[11] Gocheva, E., \& Sotirov, S. (2008). Modelling of the Verification by Iris Scanning by Generalized Nets. Proceedings of Ninth International Workshop on Generalized Nets, Sofia, 4 July 2008, 9-13.

[12] Ikonomov, N. (2017). GNDraw - Software Application for Creating Generalized Nets. Issues in Intuitionistic Fuzzy sets and Generalized Nets, 13, 61-71.

[13] Michalıkova, A. (2019). Intuitionistic fuzzy sets and their use in image classification. Notes on Intuitionistic Fuzzy Sets, 25(2), 60-66.

[14] Parvathi, R., Gluhchev, G., \& Atanassov, K. (2008). Generalized Net Model of Face Recognition. Proceedings of Ninth International Workshop on Generalized Nets, Sofia, 4 July 2008, 102-105.

[15] Petkov, T., Kostadinov, T., Sotirov, S., \& Krawczak, M. (2017). An intuitionistic fuzzy facial recognition approach by eigenvalues. Notes on Intuitionistic Fuzzy Sets, 23(2), $111-118$.

[16] Petkov, T., Sotirov, S., \& Surchev, S. (2016). Generalized Net Model of Person Recognition Using ART2 Neural Network and Viola-Jones Algorithm. In: Atanassov K. et al. (eds) Novel Developments in Uncertainty Representation and Processing. Advances in Intelligent Systems and Computing Series, Springer, Vol. 401, 257-265.

[17] Sotirov, S. (2011). Generalized Net Model of Iris Recognition using Neural Networks. Annual of "Informatics", Section Union of Scientists in Bulgaria, 4, 127-132.

[18] Uhl, A., Busch, C., Marcel, S., \& Veldhuis, R. (2020). Handbook of Vascular Biometrics. Advances in Computer Vision and Pattern Recognition Series, Springer. 